\title{
Flexible Polyaniline/Carbon Nanotube Nanocomposite Film-based Electronic
}

\section{Gas Sensors}

\author{
Lina Xue, ${ }^{\mathrm{a}}$ Wen Wang, ${ }^{\text {a }}$ Yunlong Guo, ${ }^{\mathrm{b}}$ Guangqing Liu, ${ }^{\mathrm{a}}$ Pengbo Wan ${ }^{\mathrm{b}}$
}

${ }^{\mathrm{a} B i o m a s s}$ Energy and Environmental Engineering Research Center, Beijing University of Chemical Technology, Beijing 100029, China.

${ }^{\mathrm{b}}$ State Key Laboratory of Organic-Inorganic Composites, College of Materials Science and Engineering, Beijing University of Chemical Technology, Beijing 100029, P. R. China.

*Corresponding author: Tel.: +86-10 64429591.

E-mail address: wangwen@mail.buct.edu.cn; pbwan@mail.buct.edu.cn. 


\begin{abstract}
Real-time ammonia $\left(\mathrm{NH}_{3}\right)$ detection in anaerobic digestion is highly desirable, due to the ammonia inhibition on methane production. Here, the interconnected nanocomposite network of polyaniline (PANI) nanoparticle-coated carbon nanotube (CNT) and PANI nanofiber is fabricated by adding ammonium persulfate into CNT-containing aniline solution for PANI polymerization and film deposition. The film is assembled as high-sensitive ammonia sensors, exhibiting highly sensitive $\mathrm{NH}_{3}$ sensing from $200 \mathrm{ppb}$ to $50 \mathrm{ppm}$, fast response/recovery time, room-temperature operation without external aid, reliable flexibility and excellent selectivity to $\mathrm{NH}_{3}$ compared to other volatile organic compounds.
\end{abstract}

Keywords: anaerobic digestion; ammonia inhibition; transparent conducting films; gas sensors; polyaniline; nanocomposites 


\section{Introduction}

The rapidly growing global concerns over the structure of energy demand and the environment pollution have stimulated efforts to develop renewable energy $[1,2]$. As a method to produce renewable energy, anaerobic digestion has attracted a lot of attention in the world[3]. Anaerobic digestion technology is an important means to dispose organic solid waste, including manure, industrial waste and food waste, for preventing corruption and stink, and to produce methane by fermentation as valuable renewable energy resources for employed in vehicles after purification[4]. Organic wastes containing nitrogen, such as protein, urea and amino acid, are converted to ammonia $\left(\mathrm{NH}_{3}\right)$ by anaerobic digestion. Thus, the concentration of ammonia nitrogen will accumulate in a long term. However, ammonia inhibition of anaerobic digestion caused by ammonia accumulation is one of the main reasons to lead the low efficiency and poor stability for anaerobic digestion[5]. High concentration of ammonia has inhibitory and toxic effects on anaerobic digestion operation for degrading organic matters and methane production[6, 7]. Thus, it is highly expected that ammonia inhibition phenomenon can be discovered earlier and timely for real-time adjustment of reaction conditions to eliminate the inhibitory effect on anaerobic digestion for both environmental and economic concern. Therefore, real-time ammonia detection in anaerobic digestion by high-sensitive room-temperature electronic gas sensors, is highly desirable. 
Some ammonia detection instruments have actually been available, such as gas chromatograph and the traditional ceramics tube or inter-finger probe based gas sensing devices. However, they are lack of relative portability, real-time sensing, low cost, transparency and flexibility [8, 9]. Therefore, they cannot meet the growing future application call for flexible gas sensors.

Recently, flexible conductive film-based gas sensors have attracted widely scientific attention due to the wearability, flexibility, transparency and compatibility over curved substrates of integrated electronics[10-14]. Among the various nanomaterials-based flexible electronic gas sensors, CNT film-based sensors demonstrated stable room-temperature $\mathrm{NH}_{3}$ sensing performance[15-18]. But they displayed relatively low sensing performance. Meanwhile, polyaniline (PANI) based sensors have been well established due to the facile synthesis, simple acid/base doping/dedoping chemistry and high $\mathrm{NH}_{3}$ sensing response[19-21]. A dramatic conductance decrease can be observed for PANI gas detection by transforming emeraldine salt form of PANI into its emeraldine base form exposed to the strong electron donating $\mathrm{NH}_{3}$. However, they are lack of long-term environmental stability. Conductive polymer nanocomposites based gas sensors have been well reported. J. F. Feller and co-workers fabricated polycarbonate-CNTs transducers with hierarchical structure prepared by spray layer by layer for vapour sensing[22]. S. Abdulla and coworkers demonstrated a room temperature gas sensor based on PANI/CNTs nanocomposite for ammonia detection[23]. However, compared to 
these sensors, highly sensitive room-temperature electronic gas sensors are greatly desirable. Thus, the combination of these materials into nanocomposite network films with intrinsic mobility, chemical stability, and high-sensitive $\mathrm{NH}_{3}$ performance for $\mathrm{NH}_{3}$ sensors remains to be addressed.

Herein, we fabricated a hierarchical polyaniline/carbon nanotube (PANI/CNT) nanocomposite network films to be assembled as gas sensors for high-sensitive $\mathrm{NH}_{3}$ detection. The hierarchical nanocomposite films are obtained by adding ammonium persulfate (APS) into CNT-containing aniline solution for in-situ PANI polymerization and film deposition on PET substrate. The PANI nanoparticle coated CNT and PANI nanofiber were successfully interconnected to form the hierarchical nanocomposite network. The assembled gas sensor exibits highly sensitive $\mathrm{NH}_{3}$ sensing from 200 ppb to $50 \mathrm{ppm}$, fast response/recovery time, room-temperature operation without external aid, and reliable flexibility (Figure 1). The hierarchical nanocomposite film sensor demonstrated a better sensing response and cycle stability than CNT and PANI based films, which thus holds a great promise for real-world sensor applications.

\section{Experimental details}

\subsection{Materials}


Ammonium persulfate (APS), concentrated $\mathrm{HCl}$, concentrated $\mathrm{H}_{2} \mathrm{SO}_{4}$, concentrated $\mathrm{HNO}_{3}$ and ethanol, were purchased from Beijing Chemical Reagent Factory. Aniline (distilled before use) was purchased from J\&K Chemical. Polyethylene terephthalate (PET, $125 \mu \mathrm{m})$ film was obtained from Hui Zhixing Company (Hangzhou, China). Multi-walled carbon nanotubes are commercially obtained from Cnano (FloTubeTM 9000).

\subsection{Preparation of PANI/CNT Nanocomposite Films}

The $25 \mathrm{mg}$ multi-walled carbon nanotubes are added into the the mixture of $45 \mathrm{ml} \mathrm{H}_{2} \mathrm{SO}_{4}$ and $15 \mathrm{ml} \mathrm{HNO}_{3}$ acid, and sonicated for $8 \mathrm{~h}$, then diluted to neutral state[24]. The functionalized CNTs are dispersed in ethanol solution to prepare $0.5 \mathrm{mg} / \mathrm{ml} \mathrm{CNT}$ solution.

$200 \mu \mathrm{L}$ functionalized CNTs ethanol solution was added to $15 \mathrm{~mL}$ of $1 \mathrm{M}$ $\mathrm{HCl}$ and sonicated for $15 \mathrm{~min}$. Then $82 \mu \mathrm{L}$ aniline was added. The mixture was refrigerated in the refrigerator for $15 \mathrm{~min}$ at $4{ }^{\circ} \mathrm{C}$. Then, $15 \mathrm{ml}$ of $0.06 \mathrm{M}$ APS in $1 \mathrm{M} \mathrm{HCl}$ was dropped into the above solution. After that, the PET substrate treated by $\mathrm{O}_{2}$ plasma was dipped into the above solution to react for $0.5 \mathrm{~h}$ at $4{ }^{\circ} \mathrm{C}$. Then the films were taken out and washed with ethanol and dried at room temperature for further characterization. The PANI fiber films were prepared by the same methods without adding CNTs. And CNT film was prepared by dropping $200 \mu \mathrm{L}$ CNT ethanol solution onto PET substrate. 


\subsection{Gas Sensing Measurement}

The gas sensing measurement was performed in a WS-30A measuring system (Zhengzhou Winsen Electronics Technology, China) as reported previously[9]. The functional films $(8 \mathrm{~mm}$ by $8 \mathrm{~mm}$ ) were attached on the probes of voltage-testing devices with silver paint (the operating humidity range at $30-47 \%$, and the operating temperature at $25-35{ }^{\circ} \mathrm{C}$ in Beijing), as shown in Figure S1. By dropping calculated amount of ammonium hydroxide onto a hot plate in the chamber, the corresponding $\mathrm{NH}_{3}$ concentrations were rapidly generated in the chamber. The response of $\mathrm{NH}_{3}$ is defined as the normalized resistance change.

$\mathrm{R}=\left(\mathrm{R}_{\mathrm{g}}-\mathrm{R}_{0}\right) / \mathrm{R}_{0}=\Delta \mathrm{R} / \mathrm{R}_{0}$

where $\mathrm{R}_{\mathrm{g}}$ is the resistance of the film after exposure to gas analytes and $\mathrm{R}_{0}$ is the resistance of the film in the air.

\subsection{General Techniques}

SEM images were obtained from a Zeiss Supra 55 instrument at a voltage of $20 \mathrm{kV}$. UV-vis transmittance spectra were recorded by a Shimadzu UV-3150 UV spectrophotometer. Fourier transform infrared (FTIR) spectra were collected on a Nicolet 6700 FTIR spectrometer. The sheet resistance was measured by four-probe tester (RST-8). 


\section{Results and discussion}

\subsection{Morphology and structure}

Hierarchical PANI/CNT nanocomposites were obtained, as shown in Figure $2 \mathrm{a}$ and 2c. After treatment with inorganic acid, CNTs were functionalized with various oxygenated groups (e.g., carbonyl, hydroxyl and epoxy groups) (Figure S2), providing well dispersibility for CNTs in aqueous solutions[24]. The functionalized groups acted as active sites for attaching anilinium ions via electrostatic attraction for the further PANI polymerization $[25,26]$. By adding APS into CNT-containing 0.06 $\mathrm{M}$ aniline solution (the ratio of [aniline]/[APS)]=1:1) for in-situ PANI polymerization and film depostion, the hierarchical nanocomposite with the interconnection of PANI nanoparticle-coated CNT and PANI nanofiber were obtained and deposited on PET substrate. For comparison, the PANI fiber aggregates were obtained in aniline polymerizing solution without CNTs on PET film, as demonstrated in Figure $2 \mathrm{~b}$ and $2 \mathrm{~d}$. In our previous report, after aniline was dropped into the mixed solution of CNT and APS (an aniline concentration at $0.01 \mathrm{M}$ and a ratio of [aniline]/[APS] at 1.75:1), PET was dipped into the solution to react for $6 \mathrm{~h}$, $8 \mathrm{~h}, 10 \mathrm{~h}$, or $12 \mathrm{~h}$. The hierarchical nanocomposite network of the PANI nanorods-coated FMWCNTs was obtained[17].

FTIR spectra were conducted to confirm the formation of the hierarchical PANI/CNT nanocomposites. As shown in Figure 3, for CNTs, the main peaks 
at $1630 \mathrm{~cm}^{-1}$ are attributed to the stretching of the $\mathrm{C}=\mathrm{C}$ in the quinoid ring. For PANI, characteristic bands are observed at $1560 \mathrm{~cm}^{-1}(\mathrm{C}=\mathrm{C}$ stretch of the quinoid ring), $1470 \mathrm{~cm}^{-1}$ (benzenoid ring) and $1300 \mathrm{~cm}^{-1}(\mathrm{C}-\mathrm{N}$ stretch of the second aryamine), respectively[25]. For PANI/CNT nanocomposite, the main peaks centred at $1575 \mathrm{~cm}^{-1}$ and $1470 \mathrm{~cm}^{-1}$ are attributed to the $\mathrm{C}=\mathrm{C}$ stretching vibration of the quinoid ring and the benzenoid ring in the PANI chains, indicating the presence of the emeraldine salt state of PANI

\subsection{Gas-sensing properties of PANI/CNT nanocomposite}

$\mathrm{NH}_{3}$ is a volatile, corrosive and poisonous gas, which can cause inhibitory and toxic effects on anaerobic digestion for methane production[27]. The prepared hierarchical PANI/CNT nanocomposite films were assembled as flexible gas sensors at room temperature for highly sensitive $\mathrm{NH}_{3}$ sensing to potential real-time discovery of ammonia inhibition phenomenon. Figure 4 demonstrates the gas sensing response for PANI/CNT nanocomposite, PANI fiber aggregate and the CNT film devices to different concentrations of $\mathrm{NH}_{3}$ from $200 \mathrm{ppb}$ to $50 \mathrm{ppm}$ at room temperature (the detailed response to $\mathrm{NH}_{3}$ from $200 \mathrm{ppb}$ to $1500 \mathrm{ppb}$ in Figure 4b). The response increased gradually with the increased $\mathrm{NH}_{3}$ concentration. Meanwhile, the response for the PANI/CNT nanocomposite film is better than that for the PANI fiber aggregate and the CNT film devices, displaying the special synergistic effects of PANI/CNT nanocomposite by combined excellent properties of individual materials for 
high-performance gas sensing. The sensing response of PANI/CNT nanocomposite could still be obtained for $\mathrm{NH}_{3}$ concentration as low as $200 \mathrm{ppb}$, implying its high-sensitive $\mathrm{NH}_{3}$ sensing in chemical detection.

Meanwhile, the selectively sensing response to $\mathrm{NH}_{3}$ for the PANI/CNT nanocomposite network film was shown in Figure 5a, compared to other volatile organic compounds with the likely concentrations of interfering gases inside a potential fermentation reactor $[1,3,6]$. The sensing repeatability for PANI/CNT nanocomposite, the PANI fiber aggregate and the CNT filmsensors was displayed in Figure 6, showing well $\mathrm{NH}_{3}$ sensing cycles. The reliable flexibility of the chemical gas sensor device is vitally important for potential integration into wearable electronics. Thus, the flexibility of chemical gas sensing performances was measured. As shown in Figure 5b, no obvious changes were observed for the sensing response in bent and extending states after 800 bending/extending cycles at room temperature, due to the superior confined nanocomposite network film, revealing the reliable and robust flexibility of the device.

\subsection{Sensing mechanisms of PANI/CNT nanocomposite to $\mathrm{NH}_{3}$}

As can be seen from Figure S3, the response/recovery time is 85 s/20 s, respectively. This high-sensitive sensing performance could be attributed to the synergistic properties of CNT and PANI, the interconnected nanocomposite network with high surface area (Figure 7)[28]. Firstly, the nanocomposite network with relatively high surface area $\left(54.187 \mathrm{~m}^{2} / \mathrm{g}\right)$, compared to 43.296 
$\mathrm{m}^{2} / \mathrm{g}$ for PANI, is helpful to the reversible adsorption of more $\mathrm{NH}_{3}$ for the enhanced sensing response. Secondly, the interconnected network worked as efficiently sensing channels to strengthen the fast charge transport. Thirdly, electrons provided from the adsorbed $\mathrm{NH}_{3}$ molecules onto PANI, transfer easily from PANI to CNT, because of the lower conductivity of PANI and lower energy barrier between PANI and carbon nanomaterials $(\sim 101 \mathrm{meV})$. Then, the electrons effectively transfer from CNT to the PANI fiber due to lower energy barrier, and finally to the electrodes[19-21,28-31]. Therefore, the sensing response was effectively improved in PANI/CNT nanocomposite network.

\section{Conclusions}

In conclusion, we have fabricated a real-time ammonia $\left(\mathrm{NH}_{3}\right)$ detection sensor for potential sensing ammonia in anaerobic digestion for maximum the renewable energy recovery because of the ammonia inhibition of anaerobic digestion for producing renewable energy sources. The sensor was assembled from a hierarchical PANI/CNT nanocomposite network film fabricated by adding APS into CNT-containing aniline solution for PANI polymerization and simultaneous film depostion. It exhibited highly sensitive $\mathrm{NH}_{3}$ sensing from $200 \mathrm{ppb}$ to $50 \mathrm{ppm}$, fast response/recovery time ( $85 \mathrm{~s} / 20 \mathrm{~s})$, room-temperature operation without external aid, reliable flexibility and excellent selectivity to $\mathrm{NH}_{3}$ compared to other volatile organic compounds. The excellent sensing performance is probably ascribed to the synergetic effects of PANI and CNT, 
the high surface area $\left(54.187 \mathrm{~m}^{2} / \mathrm{g}\right)$ of nanocomposite films, and effective network sensing channels. The film with simple preparation, high sensitivity, small size and robust flexibility, could be implanted into electronic devices for potentially monitoring $\mathrm{NH}_{3}$ in anaerobic digestion in real-time for the high efficiency and better stability of anaerobic digestion for renewable energy sources.

\section{Acknowledgements}

This study was funded by Science and Technology Commission of Beijing Municipality (Z151100001115006), National Science Foundation of China (51508015), Fundamental Research Funds for the Central Universities (buctrc201505, ZY1510), National Natural Science Foundation of China, Beijing Natural Science Foundation (2152023), and the long-term subsidy mechanism from the Ministry of Finance and the Ministry of Education of PRC.

\section{References}

[1] A. Demirbas, Potential applications of renewable energy sources, biomass combustion problems in boiler power systems and combustion related environmental issues, Prog. Energy Combust. Sci., 31 (2005) 171-192.

[2] Z. Huang, Z. Zhang, X. Qi, X. Ren, G. Xu, P. Wan, X. Sun, H. Zhang, Wall-like hierarchical metal oxide nanosheet arrays grown on carbon cloth for excellent supercapacitor electrodes, Nanoscale, (2016) DOI: 10.1039/C6NR04020A. 
[3] L. Appels, J. Lauwers, J. Degrève, L. Helsen, B. Lievens, K. Willems, J. V. Impe R. Dewil, Anaerobic digestion in global bio-energy production: Potential and research challenges, Renew. Sust. Energ. Rev., 15 (2011) 4295-4301.

[4] P. Kumaran, D. Hephzibah, R. Sivasankari, N. Saifuddin, A. H. Shamsuddin, A review on industrial scale anaerobic digestion systems deployment in Malaysia: Opportunities and challenges, Renew. Sust. Energ. Rev., 56 (2016) 929-940.

[5] R. Rajagopal, D. I. Massé, G. Singh, A critical review on inhibition of anaerobic digestion process by excess ammonia, Bioresour. Technol., 143 (2013) 632-641.

[6] O. Yenigün, B. Demirel, Ammonia inhibition in anaerobic digestion: a review, Process Biochem., 48 (2013) 901-911.

[7] Z. Wang, F. Xu, Y. Li, Effects of total ammonia nitrogen concentration on solid-state anaerobic digestion of corn stover, Bioresour. Technol., 144 (2013) 281-287.

[8] Z. Wu, X. Chen, S. Zhu, Z. Zhou, Y. Yao, W. Quan, B. Liu, Enhanced sensitivity of ammonia sensor using graphene/polyaniline nanocomposite, Sens. Actuators. B, 178 (2013) 485-493.

[9] S. Bai, C. Sun, P. Wan, C. Wang, R. Luo, Y. Li, J. Liu, X. Sun, Transparent Conducting Films of Hierarchically Nanostructured Polyaniline Networks on Flexible Substrates for High-Performance Gas Sensors, Small, 11 (2015) 306-310.

[10] J. Wang, M. Liang, Y. Fang, T. Qiu, J. Zhang, L. Zhi, Rod-coating: towards large-area fabrication of uniform reduced graphene oxide films for flexible touch screens, Adv. Mater., 24 (2012) 2874-2878. 
[11] L. Torsi, M. Magliulo, K. Manoli, G. Palazzo, Organic field-effect transistor sensors: a tutorial review, Chem. Soc. Rev., 42 (2013) 8612-8628.

[12] C. Liao, M. Zhang, M. Y. Yao, T. Hua, L. Li, F. Yan, Flexible organic electronics in biology: materials and devices, Adv. Mater., 27 (2015) 7493-7527.

[13] H. Wu, D. Kong, Z. Ruan, P.-C. Hsu, S. Wang, Z. Yu, T. J. Carney, L. Hu, S. Fan, Y. Cui, A transparent electrode based on a metal nanotrough network, Nat. Nanotechnol., 8 (2013) 421-425.

[14] M. L. Hammock, A. Chortos, B. C. K. Tee, J. B. H. Tok, Z. Bao, 25th Anniversary Article: The Evolution of Electronic Skin (E-Skin): A Brief History, Design Considerations, and Recent Progress, Adv. Mater., 25 (2013) 5997-6038.

[15] F. Yang, X. Wang, D. Zhang, J. Yang, D. Luo, Z. Xu, J. Wei, J.-Q. Wang, Z. Xu, F. Peng, Chirality-specific growth of single-walled carbon nanotubes on solid alloy catalysts, Nature, 510 (2014) 522-524.

[16] Z. Niu, P. Luan, Q. Shao, H. Dong, J. Li, J. Chen, D. Zhao, L. Cai, W. Zhou, X. Chen, A "skeleton/skin" strategy for preparing ultrathin free-standing single-walled carbon nanotube/polyaniline films for high performance supercapacitor electrodes, Energy Environ. Sci., 5 (2012) 8726-8733.

[17] P. Wan, S. Yin, L. Liu, Y. Li, Y. Liu, X. Wang, W. Leow, B. Ma, X. Chen, Graphene Carrier for Magneto-Controllable Bioelectrocatalysis, Small, 10 (2014) 647-652. 
[18] S. Bai, C. Sun, H. Yan, X. Sun, H. Zhang, L. Luo, X. Lei, P. Wan, X. Chen, Healable, Transparent, Room-Temperature Electronic Sensors Based on Carbon Nanotube Network-Coated Polyelectrolyte Multilayers, Small, 11 (2015) 5807-5813.

[19] J. Wang, X. Zhang, X. Huang, S. Wang, Q. Qian, W. Du, Y. Wang, Forced Assembly of Water-Dispersible Carbon Nanotubes Trapped in Paper for Cheap Gas Sensors, Small, 9 (2013) 3759-3764.

[20] D. Li, J. Huang, R. B. Kaner, Polyaniline nanofibers: a unique polymer nanostructure for versatile applications, Acc. Chem. Res., 42 (2008) 135-145.

[21] P. Wan, X. Chen, Stimuli-Responsive Supramolecular Interfaces for Controllable Bioelectrocatalysis, ChemElectroChem, 1 (2014) 1602-1612.

[22] J. Lu, B. Kumar, M. Castro, J. F. Feller, Vapour sensing with conductive polymer nanocomposites (CPC): Polycarbonate-carbon nanotubes transducers with hierarchical structure processed by spray layer by layer, Sens. Actuators, B, 140 (2009) 451-460.

[23] S. Abdulla, T. L. Mathew, B. Pullithadthil, Highly sensitive, room temperature gas sensor based on polyaniline-multiwalled carbon nanotubes (PANI/MWCNTs) nanocomposite for trace-level ammonia detection, Sens. Actuators, B, 221 (2015) $1523-1534$.

[24] J. Xu, K. Wang, S. Z. Zu, B. H. Han, Z. Wei, Hierarchical nanocomposites of polyaniline nanowire arrays on graphene oxide sheets with synergistic effect for energy storage, ACS Nano, 4 (2010) 5019-5026. 
[25] H. Fan, H. Wang, N. Zhao, X. Zhang, J. Xu, Hierarchical nanocomposite of polyaniline nanorods grown on the surface of carbon nanotubes for high-performance supercapacitor electrode, J. Mater. Chem., 22 (2012) 2774-2780.

[26] T. Wang, Y. Guo, P. Wan, H. Zhang, X. Chen, X. Sun, Flexible Transparent Electronic Gas Sensors, Small, (2016) DOI:10.1002/smll.201601049.

[27] I. Fotidis, D. Karakashev, I. Angelidaki, The dominant acetate degradation pathway/methanogenic composition in full-scale anaerobic digesters operating under different ammonia levels, Int. J. Environ. Sci. Technol., 11 (2014) 2087-2094.

[28] Y. Guo, T. Wang, F. Chen, X. Sun, X. Li, Z. Yu, P. Wan, X. Chen, Hierarchical graphene-polyaniline nanocomposite films for high-performance flexible electronic gas sensors, Nanoscale, 8 (2016) 12073-12080.

[29] R. Yoo, J. Kim, M.-J. Song, W. Lee, J. S. Noh, Nano-composite sensors composed of single-walled carbon nanotubes and polyaniline for the detection of a nerve agent simulant gas, Sens. Actuators, B, 209 (2015) 444-448.

[30] R. G. Amorim, A. Fazzio, A. J. Silva, A. R. Rocha, Confinement effects and why carbon nanotube bundles can work as gas sensors, Nanoscale, 5 (2013) 2798-2803.

[31] R. V. Salvatierra, M. M. Oliveira, A. J. Zarbin, One-pot synthesis and processing of transparent, conducting, and freestanding carbon nanotubes/polyaniline composite films, Chem. Mater., 22 (2010) 5222-5234. 


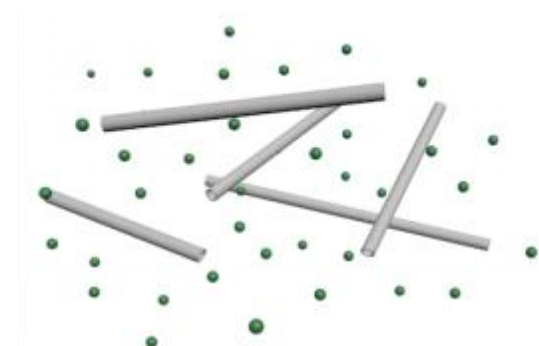

CNT-containing aniline solution

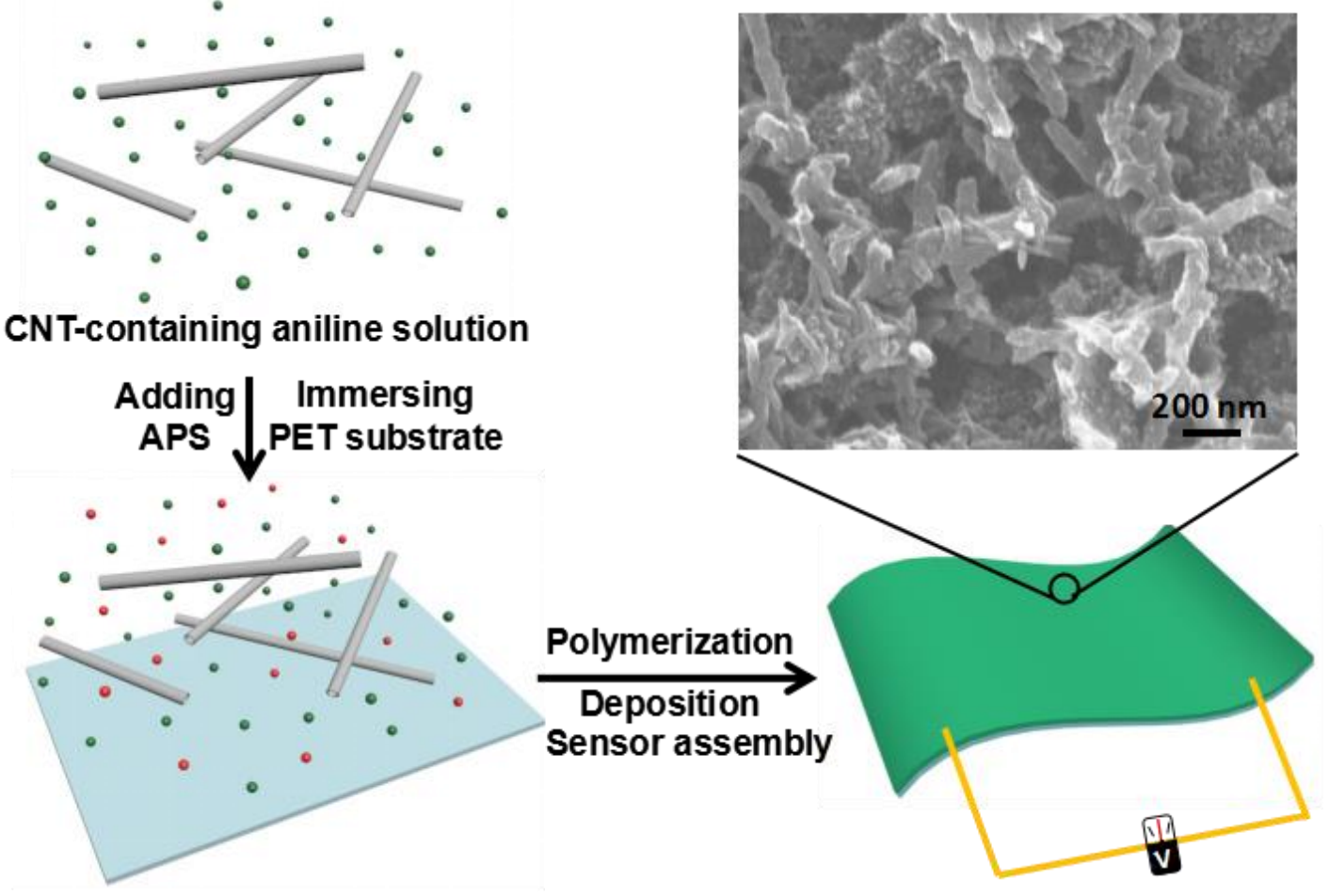

Figure 1 

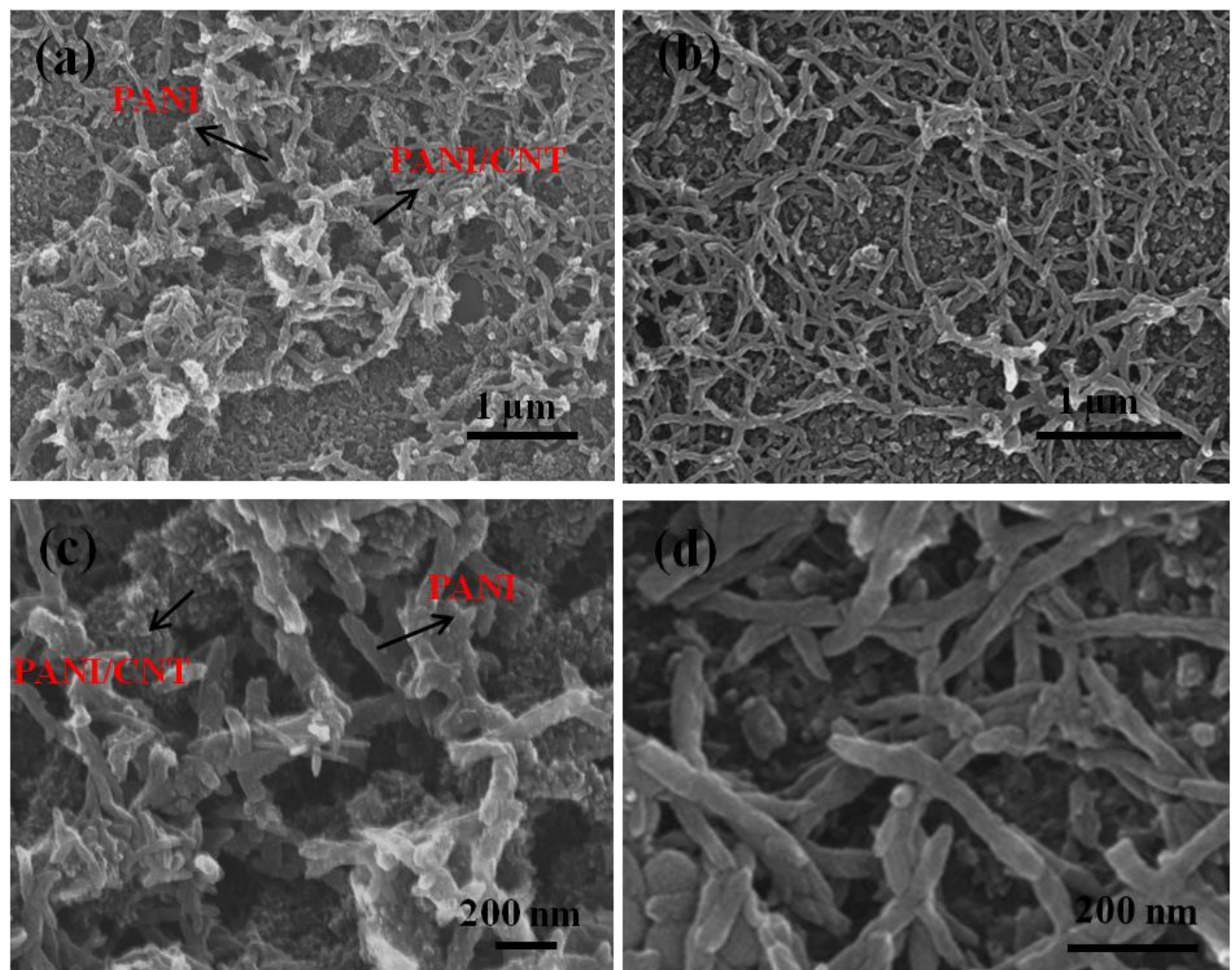

Figure 2 


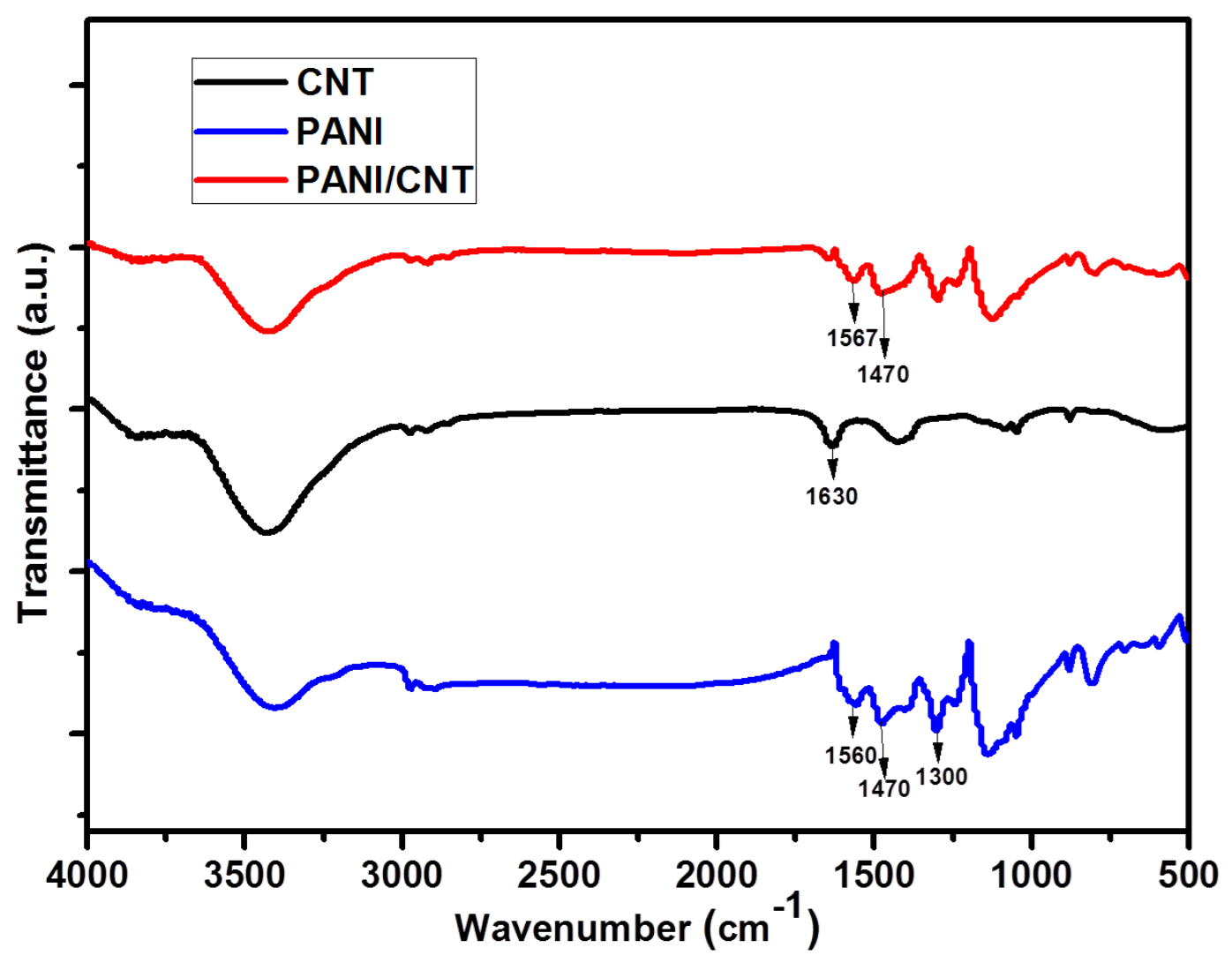

Figure 3 

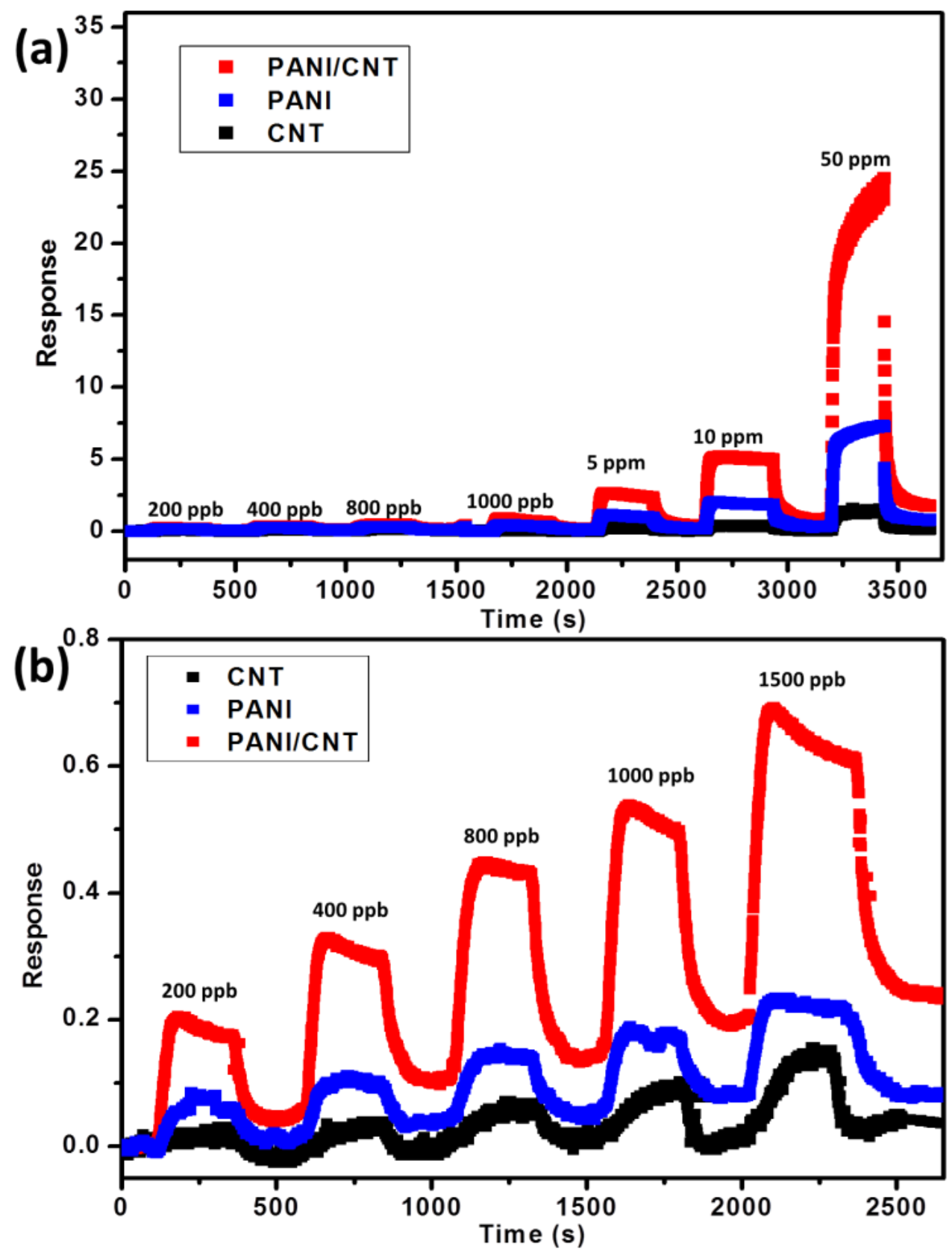

Figure 4 

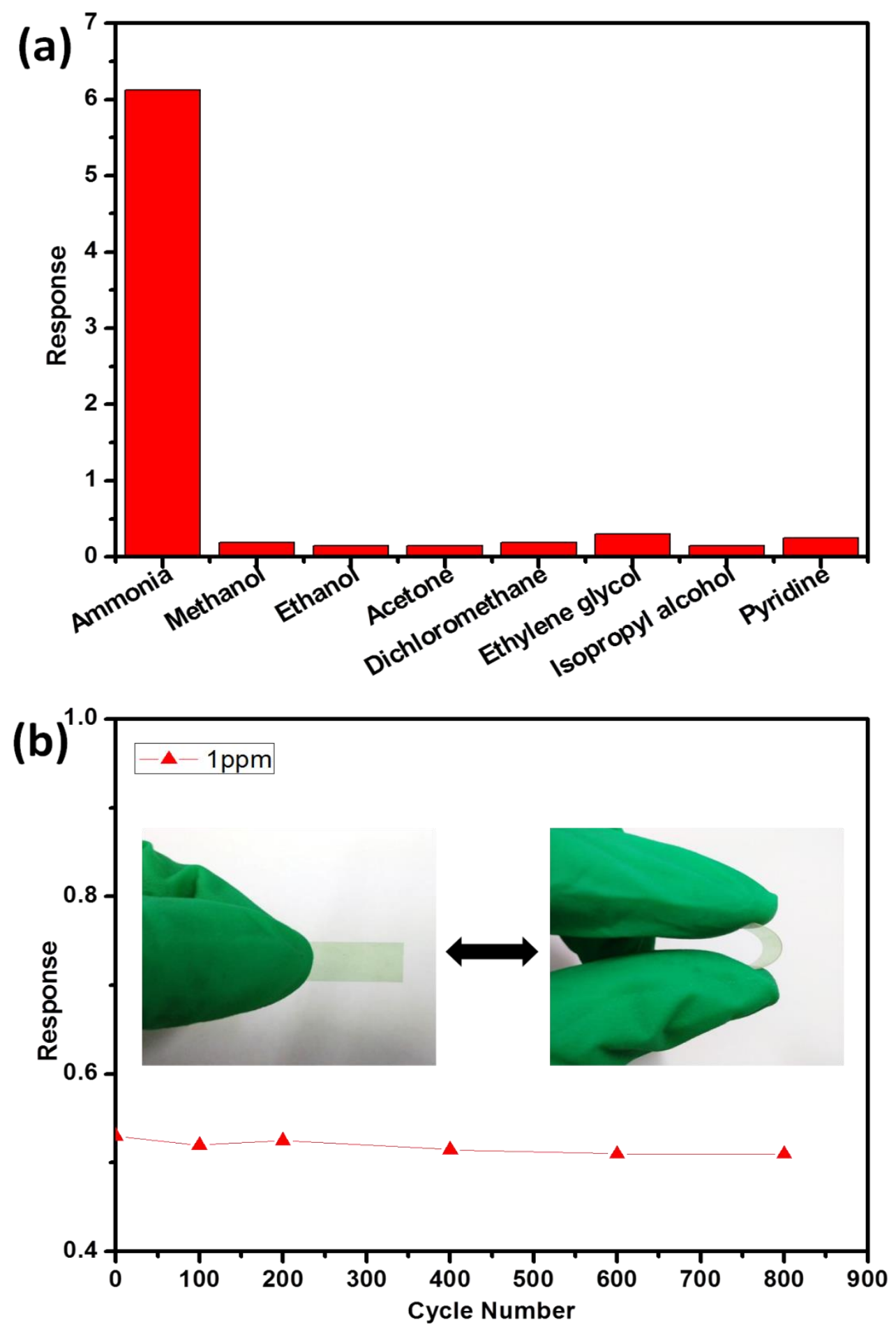

Figure 5 


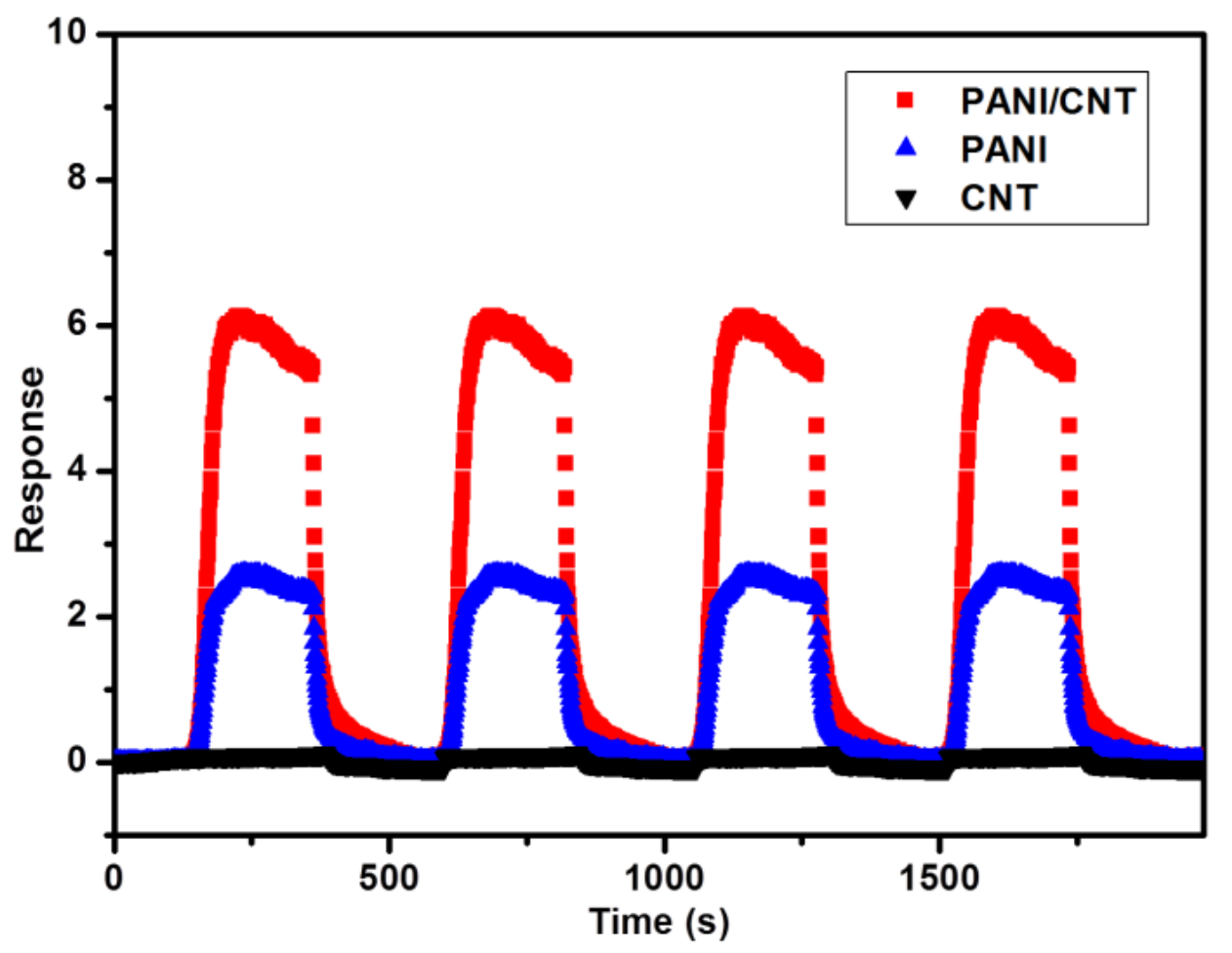

Figure 6 


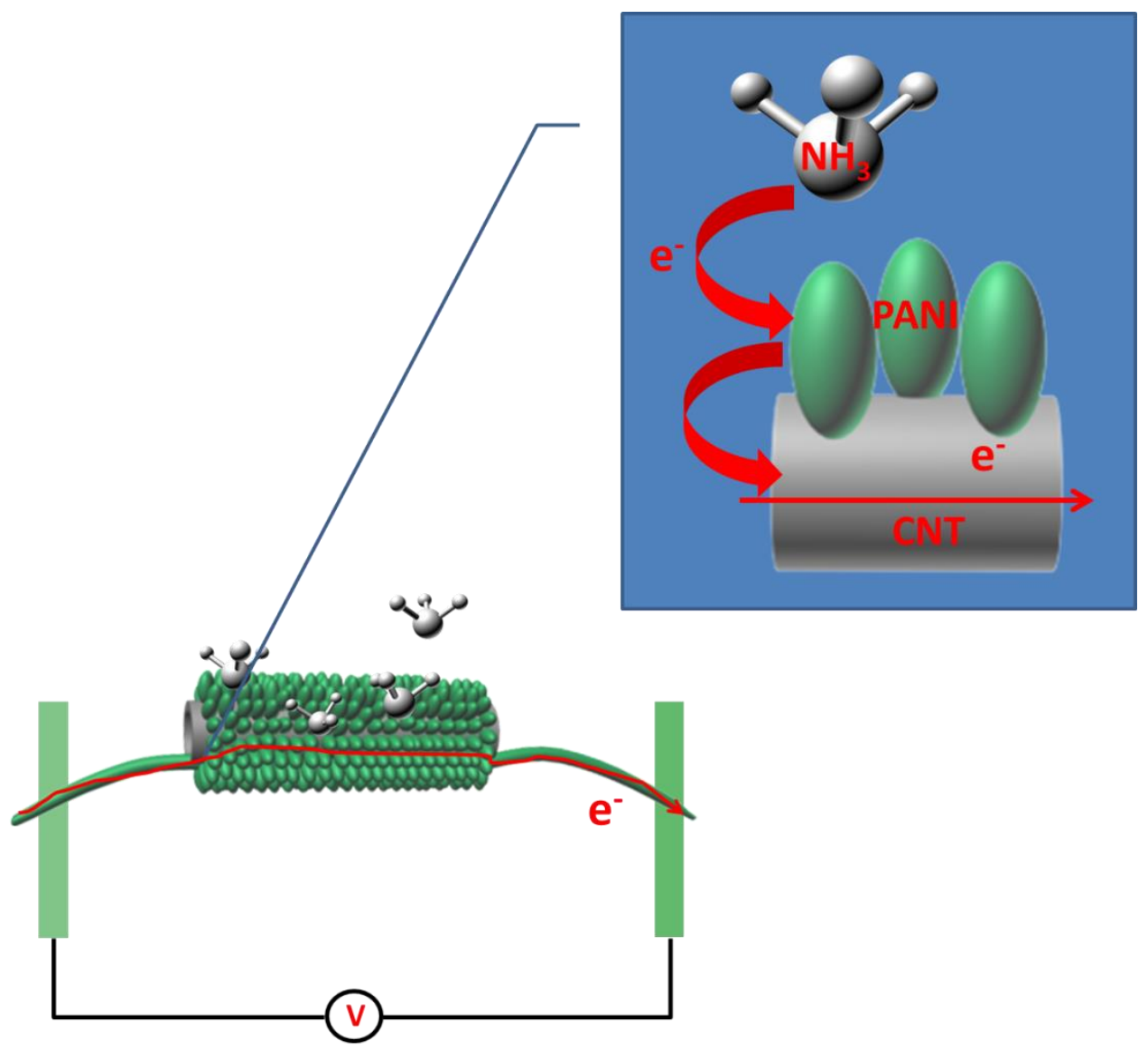

Figure 7 


\section{Figure Captions}

Figure 1. Schematic illustration for the fabrication of the interconnected nanocomposite networks of PANI nanoparticle-coated CNT and PANI nanofiber, and the assembled flexible gas sensor.

Figure 2. SEM images of (a) PANI/CNT network (scale bar: $1 \mu \mathrm{m}$ ) and (b) PANI fiber (scale bar: 1 $\mu \mathrm{m})$. Enlarged SEM images of (c) PANI/CNT network (scale bar: $200 \mathrm{~nm}$ ) and (d) PANI fiber (scale bar: $200 \mathrm{~nm})$.

Figure 3. FTIR spectra of the hierarchical PANI/CNT nanocomposite, PANI fiber and CNT.

Figure 4. (a) Gas sensing performance of PANI/CNT nanocomposite, the PANI fiber aggregate and the CNT film devices to different concentrations of $\mathrm{NH}_{3}$ from $200 \mathrm{ppb}$ to $50 \mathrm{ppm}$. (b) The detailed gas sensing response of PANI/CNT nanocomposite, the PANI fiber aggregate and the CNT film devices to different concentrations of $\mathrm{NH}_{3}$ from $200 \mathrm{ppb}$ to $1500 \mathrm{ppb}$.

Figure 5. (a) The selectively sensing response to $10 \mathrm{ppm} \mathrm{NH}_{3}$ and other volatile organic compounds for the PANI/CNT nanocomposite network film. (b) Gas sensing response of the PANI/CNT nanocomposite network film in bending and extending states to $1 \mathrm{ppm} \mathrm{NH}_{3}$.

Figure 6. The sensing repeatability for PANI/CNT nanocomposite, the PANI fiber aggregate and the CNT film sensors to $10 \mathrm{ppm} \mathrm{NH}_{3}$. 
Figure 7. The proposed $\mathrm{NH}_{3}$-sensing mechanism of PANI/CNT nanocomposite network. 


\section{Graphical Abstract}

A hierarchical polyaniline/carbon nanotube nanocomposite network film is fabricated and assembled as high-sensitive ammonia $\left(\mathrm{NH}_{3}\right)$ sensors for potentially monitoring $\mathrm{NH}_{3}$ in anaerobic digestion. It exhibits highly sensitive $\mathrm{NH}_{3}$ sensing from $200 \mathrm{ppb}$ to $50 \mathrm{ppm}$, room-temperature operation without external aid, and excellent selectivity to $\mathrm{NH}_{3}$ compared to other volatile organic compounds.

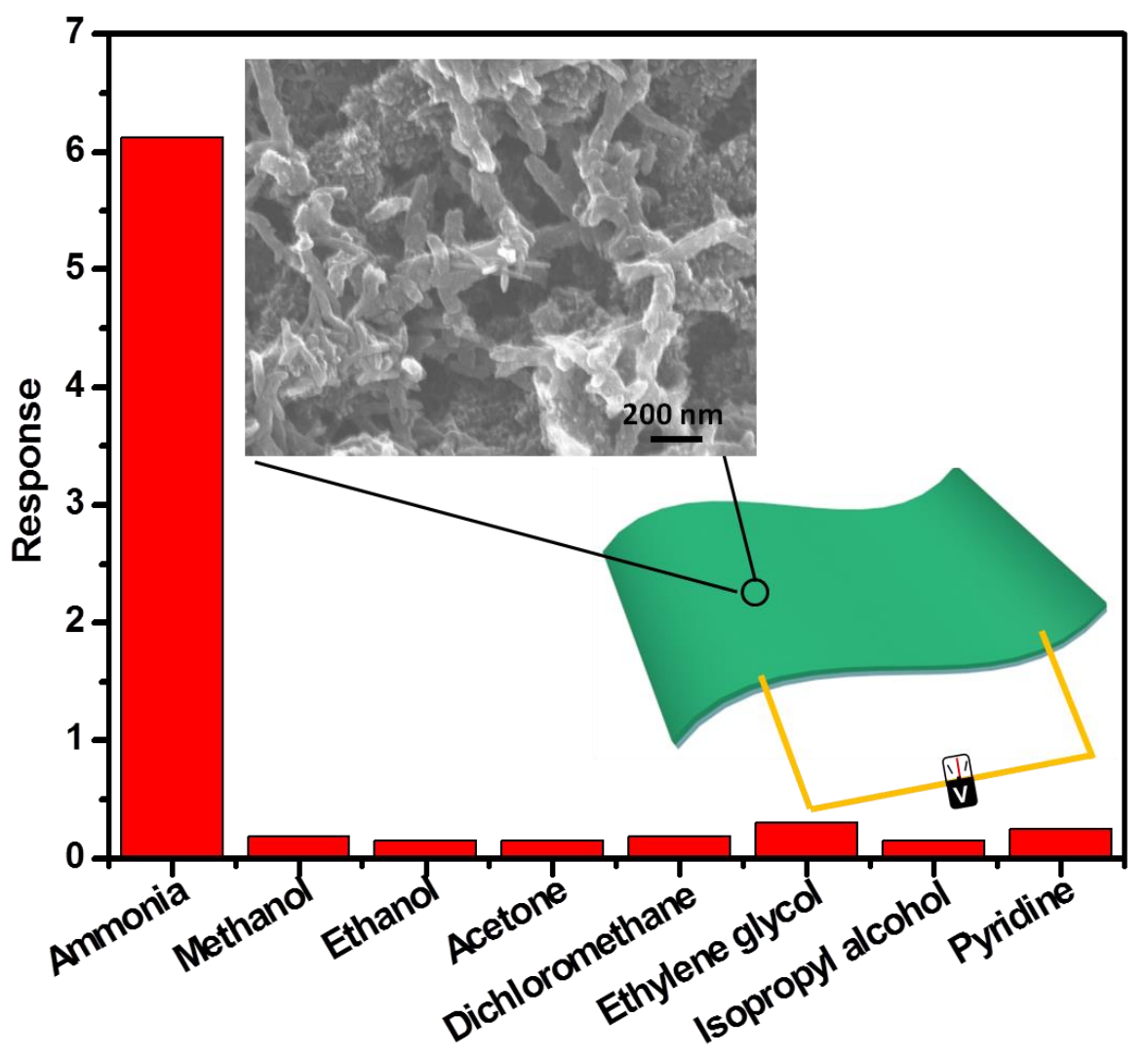




\section{Biographies}

Lina Xue received her BE degree from Hebei University of Engineering in 2014, and is currently pursuing MS degree in Environmental Engineering at Beijing University of Chemistry Technology.

Her research is focused on the development of gas sensing materials in environmental field.

Wen Wang received her Ph.D. degree from department of Environmental Engineering, Tongji University. After getting Ph.D. degree, she has been working in School of Chemical Engineering, Beijing University of Chemical Technology as an Associate Professor since then. Her research is focusing on biomass to biofuels (biogas, biohydrogen, acid) production, optimization of the anaerobic processes and development of sustainable solutions for organic waste and wastewater treatment. Dr. Wang has published about 20 academic papers, 1 book and has got 4 China Patents. She has got 8 program grants from National Science Foundation of China, Science and Technology Commission of Beijing Municipality, Fundamental Research Funds for the Central Universities etc.

Yunlong Guo received his BS degree in Chemistry from Qingdao University in 2014, and currently pursuing MS degree in Chemical engineering and technology at Beijing University of Chemistry Technology. His research is focused on the gas sensing and energy storage devices.

Professor Guangqing Liu serves as the Executive Director of Biomass Energy and Environmental Engineering Research Center at Beijing University of Chemical Technology, also the Executive Secretary-general of China Alliance for Clean Stoves. Dr. Liu has published about 
50 academic papers, 5 books and chapters and got 7 China Patents. As the PI, he got more than 20 program grants for China Ministry of Science and Technology, China Notational Science Founding, World Bank etc. He was invited as the China representatives to give presentation in more than 20 international conferences in USA, Canada, Japan, India, Indonesia, Thailand, Peru, Philippines etc.

Pengbo Wan received his B.S. degree (2006) at Wuhan University. Then he was recommended to join Prof. Xi Zhang's group as a Ph.D. candidate at Tsinghua University and got his Ph.D. degree in 2011. During his Ph.D. study, he worked as an exchange Ph.D. student at University of Leuven, Belgium. After working as a research fellow at Nanyang Technological University in Singapore, he joined Beijing University of Chemical Technology as an Associate Professor in 2013. His research interests include organic/inorganic hybrid nanomaterials for energy conversion and storage, stimuli-responsive biointerface, bioelectrocatalysis, supramolecular assembly, and nanoelectronics. 